\title{
HYDROACOUSTIC OBSERVATIONS OF WEAK EARTHQUAKES IN SHALLOW WATERS OF THE SOUTHERN KURIL ISLANDS
}

\author{
A. S. Borisov ${ }^{1}$, S. A. Borisov ${ }^{1}$, B. W. Levin ${ }^{1}$, E. V. Sasorova ${ }^{2}$ \\ ${ }^{1}$ Institute of Marine Geology and Geophysics, FEB RAS, Yuzhno-Sakhalinsk, Russia \\ ${ }^{2}$ Institute of Oceanology, RAS, Moscow, Russia
}

\begin{abstract}
Results of hydroacoustic observations of signals from weak earthquakes in natural conditions in the region of the Southern Kuril Islands are presented. Some earthquakes were registered by the the Yuzhno-Kurilsk Seismic Station, other were only recorded by hydrophone stations. The observations were specific as seismic signals were recorded in shallow waters, i.e. in high noise level conditions. Hydrophones were installed in Lake Lagunnoe (Kunashir) and Khromovaya Bay (Shikotan). Our analysis of hydroacoustic records received from the hydrophone stations revealed no evident precursory response of the geological medium to weak distant events. This means that neither before the period of earthquake preparation nor during the earthquake preparation period, any geoacoustic emission was not detected. It is shown that despite the unfavourable noise level conditions, even distant weak earthquakes can be confidently registered by hydrophone stations, and pending application of proper signal processing techniques, it can be possible to determine arrival times of seismic waves and to measure parameters of seismic waves. It is also established that the frequency spectrum of acoustic signals from the weak earthquakes recordable by the hydrophone stations is continuous and of noise type in the frequency range up to 90-100 Hz. It is revealed that in some cases, weak earthquakes and microearthquakes may be forerun by low frequency signals.
\end{abstract}

Key words: earthquake, microearthquake, geoacoustic emission, hydrophone station, signal processing, wave shape, seismic wave parameters, low frequency preceding signal, shallow water observations, Southern Kuril Islands.

Recommended by S.I. Sherman 25 April 2012

Citation: Borisov A.S., Borisov S.A., Levin B.W., Sasorova E.V., 2012. Hydroacoustic observations of weak earthquakes in shallow waters of the Southern Kuril Islands. Geodynamics \& Tectonophysics 3 (2), $103-113$. doi:10.5800/GT-2012-3-2-0065.

\section{НАБЛЮДЕНИЯ СЛАБЫХ ЗЕМЛЕТРЯСЕНИЙ ГИДРОФОННОЙ СТАНЦИЕЙ НА МЕЛКОВОДЬЕ ЮЖНЫХ КУРИЛЬСКИХ ОСТРОВОВ}

\author{
А. С. Борисов ${ }^{1}$, С. А. Борисов ${ }^{1}$, Б. В. Левин ${ }^{1}$, Е. В. Сасорова ${ }^{2}$ \\ ${ }^{1}$ Институт морской геологии и геофизики ДВО РАН, Южно-Сахалинск, Россия \\ ${ }^{2}$ Институт океанологии РАН, Москва, Россия
}

Аннотация: Представлены результаты натурных гидроакустических наблюдений слабых землетрясений в районе Южных Курильских островов. Часть землетрясений была зарегистрирована и Южно-Курильской сейсмостанцией, а часть - только гидрофонной станцией. Особенностью наблюдений являлось то, что запись сейсмических сигналов проводилась на мелководье, т.е. в условиях повышенного уровня помех. Места постановки гидрофонов: озеро Лагунное (о. Кунашир) и бухта Хромовая (о. Шикотан). Анализ гидроакустических записей с гидрофонной станции 
показал, что заметной предваряющей реакции региональной геосреды на слабые отдаленные события не произошло, т.е. геоакустической эмиссии не наблюдалось ни до подготовки, ни в период подготовки событий. В работе показано, что, несмотря на неблагоприятную помеховую обстановку, даже отдаленные слабые землетрясения уверенно регистрируются гидрофонными станциями, а применение соответствующей обработки сигналов дает возможность выделять моменты вступления сейсмических волн и измерения их параметров. Установлено также, что частотный спектр акустических сигналов от слабых удаленных землетрясений, воспринимаемых гидрофонными станциями, носит непрерывный шумоподобный характер в диапазоне частот до 90-100 Гц. Обнаружено, что некоторым слабым землетрясениям и микроземлетрясениям может предшествовать низкочастотный упреждающий сигнал (НУС).

Ключевые слова: землетрясение, микроземлетрясение, геоакустическая эмиссия, гидрофонная станция, обработка сигналов, волновая форма, параметры сейсмических волн, низкочастотный упреждающий сигнал, наблюдения на мелководье, Южные Курилы.

\section{1. ВВЕДЕНИЕ}

Ранее исследователями отмечалось [Solov'ev, 1968; Solov'ev et al., 1989; Lappo et al., 2003], что количество зарегистрированных слабых землетрясений тектонической природы существенно возрастает, если в качестве сейсмостанций используются глубоководные донные гидрофонные станции, воспринимающие акустические (упругие) волны, распространяющиеся в воде. Поглощение акустической волны в морской среде (гидроакустической волны) на 3-4 порядка меньше, чем поглощение акустической волны той же частоты, распространяющейся в геологических структурах земной коры (сейсмической, геоакустической и т.п.). Это позволяет существенно расширить площадь, с которой возможно обнаружение слабых и микроземлетрясений, а также сигналов геоакустической эмиссии, выполняемое одной донной гидрофонной станцией.

Гидроакустические волны сейсмического происхождения могут наблюдаться не только во время землетрясений, но и в предваряющий и последующий периоды времени и занимают довольно широкий диапазон частот: от долей - единиц герца до единиц килогерца. При этом высокочастотные составляющие гидроакустических волн, которые являются продуктом акустической эмиссии в твердых породах грунтов, дают особенно ценную информацию для прогностического анализа. Применение же широкополосных гидрофонных станций позволяет регистрировать подводные акустические сигналы в этом диапазоне частот [Levin et al., 2010].

В статье приводятся и обсуждаются некоторые результаты гидрофонных наблюдений, выполнявшихся в рамках экспедиционных работ на островах Кунашир и Шикотан в 2007 и 2009 гг. За время наблюдений не было обнаружено геоакустических сигналов, вызванных подготовкой сильных землетрясений, но были зарегистрированы десятки слабых землетрясений ( $\mathrm{K} \leq 10.6$, где $\mathrm{K}$ - энергетический класс землетрясения по С.Л. Соловьеву, используемый в Сахалино-Куриль- ском регионе). Запись сейсмических сигналов проводилась на мелководье, в закрытых (внутренних) акваториях. Особенностью таких наблюдений является как повышенный уровень помех, так и влияние на регистрируемые сигналы характеристик ограниченного водного бассейна и региональной геологии.

В настоящей статье впервые представлены результаты широкополосных гидрофонных наблюдений слабых землетрясений на мелководье.

\section{2. КРАТКИЙ ОБЗОР ПРОБЛЕМЫ}

Организация малошумных глубоководных и даже шельфовых гидрофонных наблюдений в настоящее время связана с большими трудностями, вызванными в основном причинами экономического характера. Гораздо менее затратными являются гидрофонные наблюдения на мелководье, выполняемые, например, в рамках сухопутных научных экспедиций. Недостатками исследований в подобных экспедиционных работах являются, во-первых, ограниченность периодов наблюдений временем экспедиции и, во-вторых, отсутствие возможности устанавливать гидрофонные станции достаточно далеко от береговой линии, т.е. в зоне с низким уровнем акустических шумов, вызванных приливными явлениями у берегов. Проблема увеличения продолжительности непрерывных наблюдений может быть решена на основе современной электронной элементной базы путем создания автономных малогабаритных гидрофонных станций с низким потреблением энергии от источника электропитания. Проблема, связанная с неблагоприятной помеховой обстановкой в прибрежных районах наблюдений, может быть частично снята путем фильтрации шумовых помех и частотно-временного анализа полученных реализаций, а также установкой гидрофонов в менее шумных акваториях - в озерах. В последнем случае при регистрации достаточно низкочастотных (десятки герц и ниже) спектральных составляющих в акустиче- 
ских сигналах, вызванных удаленными землетрясениями, заметной разницы между прибрежными морскими и озерными исследованиями не должно наблюдаться, так как практически вся часть пути, по которому распространяются акустические (сейсмические) волны, приходится на земную кору и осадочный слой, а не на водную акваторию.

\section{3. МЕТОДЫ, ФАКТИЧЕСКИЕ ДАННЫЕ И АНАЛИЗ}

Гидрофонные наблюдения землетрясений проводились в экспедициях на острова Кунашир (озеро Лагунное) и Шикотан (бухта Хромовая). Глубина места установки донного гидрофона на озере Лагунном составляла около 1.5 м, а в бухте Хромовой - от 2 до 4 м.

Наблюдения акустических сигналов на Кунашире проводились в течение трех периодов: с 10 по 15 августа 2007 г., с 19 по 24 сентября 2007 г., с 18 по 22 мая 2009 г. Как отмечалось выше, в эти периоды наблюдений были зарегистрированы десятки относительно слабых землетрясений класса $\mathrm{K} \leq 10.6$. Так, например, в первый период гидрофонной станцией было зарегистрировано пятнадцать землетрясений. Сейсмические сигналы от этих землетрясений были зарегистрированы также сейсмостанцией «Южно-Курильск», находящейся в 6 км от места установки гидрофонной станции.

Гидроакустические наблюдения на острове Шикотан проводились в период с 18 по 22 июня 2009 г. Здесь было зарегистрировано одно локальное микроземлетрясение и несколько региональных слабых землетрясений.

Для приема гидроакустических сигналов применялись гидрофоны, изготовленные на основе пьезокерамических сфер диаметром 50 мм. Чувствительность гидрофонов в частотном диапазоне от единиц килогерца и ниже составляет приблизительно 200 мкВ/Па. Пороговая чувствительность таких гидрофонных приемников упругих колебаний не хуже 0.005 Па. Это означает, что гидрофон может воспринимать акустические волны, возбуждаемые донной поверхностью океана, колеблющейся со скоростью:

$$
\xi=\left(\frac{P}{\rho c}=\frac{0.005}{1.5 \cdot 10^{6}}\right) \approx 3 \cdot 10^{-9} \mathrm{M} / \mathrm{c},
$$

где $P$ - звуковое давление; $\rho$ - плотность воды; $c$ скорость звука. Такой колебательной скорости соответствует амплитуда колебательного смещения поверхности грунта $\xi$, равная:

$$
\xi=\frac{\xi}{\omega},
$$

где $\omega$ - круговая частота, равная $2 \pi \varphi$, где $\varphi$ - линейная частота. Например, при колебаниях на частоте 1 Гц колебательное смещение поверхности грунта составит приблизительно $5 \cdot 10^{-10} \mathrm{M}$, а на частотах 100-1000 Гц, характерных для геоакустической эмиссии, будут зарегистрированы колебательные смещения грунта с амплитудой, равной: $\xi \approx 5 \cdot 10^{-12}-5 \cdot 10^{-13}$ м. Как видим, гидрофоны обладают высокой чувствительностью к колебательным смещениям грунтов в районе их установки.

Для записи сигналов использовался регистратор типа «Дельта-Геон 02», сигналы на который подавались с гидрофонов по электрическому кабелю через согласующий усилитель. Здесь следует отметить, что, ввиду довольно значительной мощности потребления электроэнергии, автономность регистратора не высока и составляет менее 20 суток при источнике питания энергоемкостью 100 А/ч. Динамический диапазон измерительного тракта составлял 96 дБ, верхняя граничная частота измерений, в зависимости от используемой частоты дискретизации, устанавливалась в пределах от 100 до 400 Гц.

При постобработке для выделения сигналов применялась частотная фильтрация: для удаления приливных шумов использовались фильтры верхних частот с частотами среза от 2 до 3 Гц, а для удаления шумов техногенного характера, проявляющихся на дискретных частотных составляющих, но нестационарных во времени, - заграждающие фильтры с адаптацией частот подавления к частотам шумов.

Ниже, на рис. 2-7, приведены волновые формы и спектрограммы некоторых гидрофонных записей гидроакустических сигналов, зарегистрированных в озере Лагунном на Кунашире. Время на осциллограммах указано в секундах относительно начала записи, частота дискретизации - 250 Гц.

Гидроакустические сигналы возбуждались слабыми региональными землетрясениями, данные о которых (согласно сейсмологическому бюллетеню сейсмостанции «Южно-Курильск») сведены в табл. 1. Здесь отметим, что три последних события, отмеченные в таблице, сейсмостанцией зарегистрированы не были.

Рассмотрим события № 1516, № 833 и № 1515, гидрофонные записи которых сделаны в наиболее неблагоприятной помеховой обстановке за все время наблюдений. Карта эпицентров землетрясений представлена на рис. 1.

Рис. 2-4, a, иллюстрируют волновые формы без применения обработки (первичные записи). Видно, что по волновой форме нефильтрованного сигнала практически невозможно определить природу его происхождения, а в некоторых случаях даже выделить событие на фоне помех. Так, например, на рис. 2 показаны волновые формы и спектрограммы сигнала от удаленного на расстояние $\mathrm{D}=665$ км землетрясения № 1516 класса K=10.6, зарегистрированного 11.08.2007 г. Здесь особенно хорошо видны результаты примененной фильтрации (рис. 2, с и d). На волновой форме после обработки отчетливо выражены моменты прихода прямых $\mathrm{P}$ и $\mathrm{S}$ волн, которые не очевидны при рассмот- 
A.S. Borisov et al.: Hydroacoustic observations of weak earthquakes...

Т а б л и ц а 1. Параметры зарегистрированных слабых региональных землетрясений

$\mathrm{T}$ a b l e 1. Parameters of recorded weak regional earthquakes

\begin{tabular}{lllll}
\hline № землетрясения & Дата & Время & Удаленность (D), км & Класс (K) \\
\hline № 1511 & 10.08 .2007 & $11: 02: 53.4$ & 120 & 8.8 \\
№ 1515 & 11.08 .2007 & $05: 28: 55.7$ & 182 & 6.7 \\
№ 1516 & 11.08 .2007 & $09: 10: 16.1$ & 665 & 10.6 \\
№ 1520 & 11.08 .2007 & $23: 55: 21.4$ & 99 & 7.5 \\
№ 833 & 18.05 .2009 & $22: 05: 04.2$ & 125 & 9.2 \\
№ 840 & 19.05 .2009 & $20: 44: 53.5$ & 161 & 8.1 \\
№ 843 & 20.05 .2009 & $06: 53: 10.7$ & - & - \\
Не отмечено & 12.08 .2007 & $12: 38: 47$ & - & - \\
Не отмечено & 12.08 .2007 & $19: 42: 40$ & - & \\
Не отмечено & 13.08 .2007 & $01: 48: 41$ & & \\
\hline
\end{tabular}

рении первичного сигнала (рис. 2, $а$ и и $b$ ). Временной промежуток между вступлениями этих волн составляет 70 с, а общая длительность $\Delta \mathrm{T}=110$ с. Зарегистрированные гидроакустические отклики на Р- и
S-волны занимают диапазон частот приблизительно до 75 Гц.

На рис. 3 представлены волновые формы и спектрограммы землетрясения № 833, такого же класса, как и



Рис. 1. Карта эпицентров землетрясений № 1516 (K=10.6), № 833 (К=10.4) и № 1515 (К=6.7), зарегистрированных гидрофонной станцией (ГС) и сейсмостанцией «Южно-Курильск» (ЮК).

Fig. 1. Earthquake epicentres map showing events № 1516 (K=10.6), № 833 (K=10.4), and № 1515 (K=6.7) recorded by the hydrophone station (ГС) and the Yuzno-Kurilsk seismic station (ЮK). 



Рис. 2. Волновая форма $(a, c)$ и спектрограмма $(b, d)$ землетрясения № 1516 (дата - 11.08.2007 г., время - 09:10:16.1; $\mathrm{D}=665$ км, $\mathrm{K}=10.6)$, зарегистрированного гидрофонной станцией: $a, b-$ первичная запись; $c, d$ - сигнал после фильтрации.

Fig. 2. Wave shape $(a, c)$ and spectrogram $(b, d)$ of event № 1516 (at 09:10:16.1 on 11.08.2007; $\mathrm{D}=665 \mathrm{~km} ; \mathrm{K}=10.6$ ) recorded by the hydrophone station: $a, b$ - initial record; $c, d$ - signal after filtering.

в предыдущем примере. Однако, несмотря на меньшую удаленность эпицентра события ( $\mathrm{D}=125$ км), полезный сигнал так же плохо выделяется на фоне шумов антропогенной природы и поверхностного волнения озера (рис. $3, a)$. Частотно-временное представление первичной записи позволяет зафиксировать появление широкополосного шумоподобного сигнала (рис. $3, b)$, а ее обработка - определить параметры зарегистрированного события (рис. $3, c$ и $d$ ). Здесь время между откликами водной среды на Р- и S- волны составляет приблизительно 17 с, а длительность события $\Delta \mathrm{T}=62$ с. Частотный диапазон - более 100 Гц и ограничен «сверху» полосой пропускания приемного тракта.

На рис. 4, $a-d$, представлены волновая форма и спектрограмма сигнала от землетрясения №1515, зарегистрированного 11.08.2007 г. Удаленность эпицентра от сейсмостанции $\mathrm{D}=182$ км, класс $-\mathrm{K}=6.7$. Фильтрация сигнала от техногенных помех позволила обнаружить не только акустический сигнал от землетрясения, длительностью 98 с, и оценить его волновую форму (рис. $4, c)$, но и предшествующий низкочастотный сигнал (рис. 5). Продолжительность этого сигнала $\Delta \mathrm{t}$ перед событием приблизительно равна 3 с, а частота -6 Гц. Сигналы подобного типа (низкочастотный упреждающий сигнал (НУС)) описаны, например, в работе [Levin, Sasorova, 1994]. Отличительная особенность настоящего сигнала от сигналов, наблюдаемых в работе [Levin, Sasorova, 1994], заключается в том, что его уровень (амплитуда) незначительно отличается от уровня сигнала, генерируемого самим событием, и составляет приблизительно 40 \% от амплитуды события в максимальной фазе. Длительность предшествующего низкочастотного сигнала составляет 3 \% от общей длительности события № 1515.

На рис. 6, $a-d$, представлены осциллограммы и спектрограммы землетрясения, зарегистрированного только гидрофонной станцией и не отмеченного в сейсмобюллетене. Здесь на волновой форме (рис. 6, a) видно, что уровень сигнала так же достаточно низкий, для того чтобы достоверно отнести его к сигналу от землетрясения. Однако время-частотное представление (рис. 6, в) позволяет сделать предварительный вы-


Рис. 3. Волновая форма $(a, c)$ и спектрограмма $(b, d)$ землетрясения № 833 (дата - 18.05.2009 г., время - 22:05:04.2; D=125 км, $\mathrm{K}=10.4)$, зарегистрированного гидрофонной станцией: $a, b$ - первичная запись; $c, d$ - сигнал после фильтрации.

Fig. 3. Wave shape $(a, c)$ and spectrogram $(b, d)$ of event № 833 (at 22:05:04.2 on 18.05.2009; $\mathrm{D}=125 \mathrm{~km} ; \mathrm{K}=10.4$ ) recorded by the hydrophone station: $a, b$-initial record; $c, d$ - signal after filtering. 

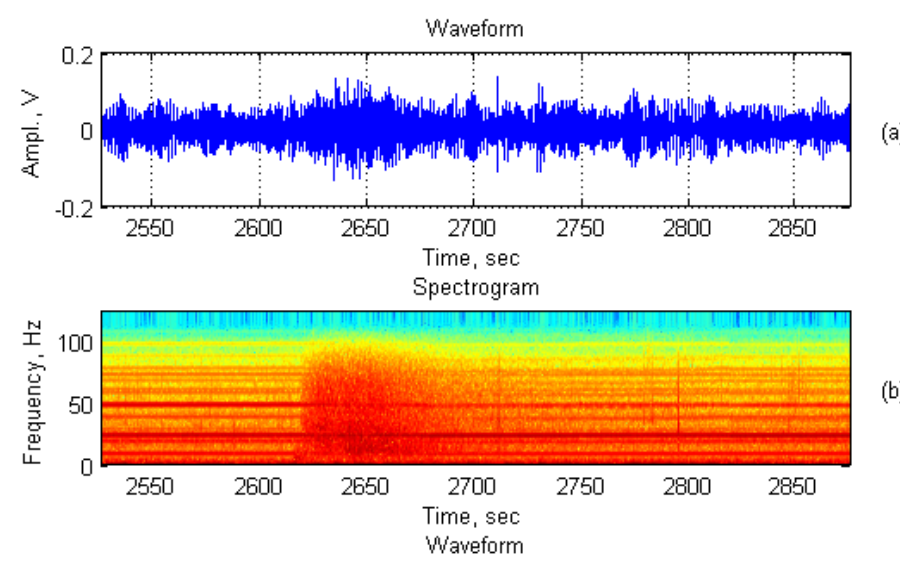

(b)

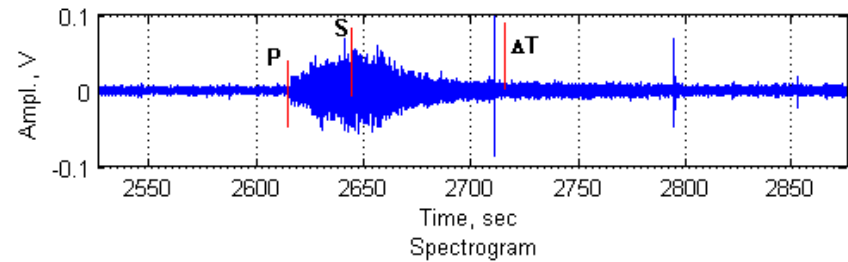

(c)



(d)

Рис. 4. Волновая форма $(a, c)$ и спектрограмма $(b, d)$ землетрясения № 1515 (дата - 11.08.2007 г., время - 05:28:55.7; $\mathrm{D}=182$ км, $\mathrm{K}=6.7)$, зарегистрированного гидрофонной станцией: $a, b$ - первичная запись; $c, d$ - сигнал после фильтрации.

Fig. 4. Wave shape $(a, c)$ and spectrogram $(b, d)$ of event № 1515 (at 05:28:55.7 on 11.08.2007; $\mathrm{D}=182 \mathrm{~km} ; \mathrm{K}=6.7)$ recorded by the hydrophone station: $a, b$-initial record; $c, d$ - signal after filtering.

вод о происхождении сигнала и приблизительно оценить времена вступления Р-волны и более мощной Sволны. Дальнейшая фильтрационная обработка позволяет уже по волновой форме (рис. 6, c) более точно

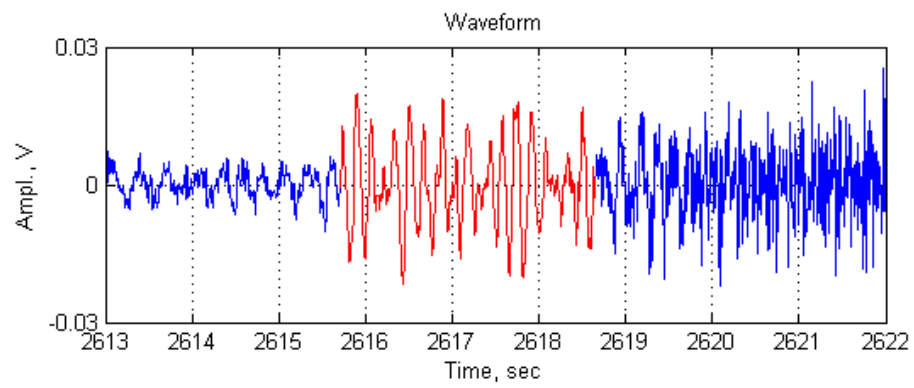

Рис. 5. Низкочастотный упреждающий сигнал перед землетрясением № 1515.

Fig. 5. Low-frequency signal prior to event № 1515.
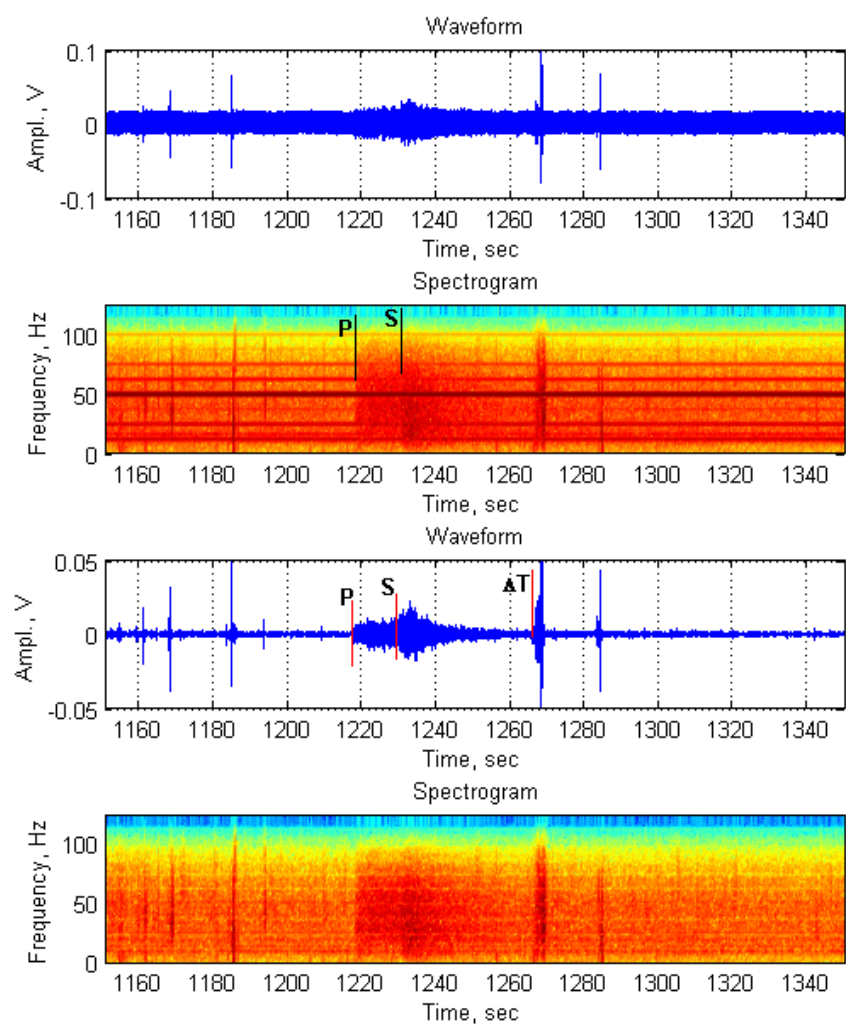

Рис. 6. Волновая форма $(a, c)$ и спектрограмма $(b, d)$ землетрясения (дата - 12.08.2007 г., время - 12:38:47, в бюллетене не отмечено), зарегистрированного гидрофонной станцией: $a, b$ - первичная запись; $c, d$ - сигнал после фильтрации.

Fig. 6. Wave shape $(a, c)$ and spectrogram $(b, d)$ of the event (at 12:38:47 on 12.08.2007; not included in the bulletin) recorded by the hydrophone station: $a, b$-initial record; $c, d$ - signal after filtering.

определить время откликов водной среды на сейсмические волны.

На рис. 7 показаны осциллограммы остальных шести слабых региональных землетрясений, произошедших в разные периоды наблюдений и зарегистрированных гидрофонной станцией. Здесь все графики представлены в одинаковых временном и амплитудном масштабах, а время $\mathrm{t}=0$ на временных шкалах всех событий соответствует вступлению Р-волн. На первичных гидроакустических записях, представленных на рис. $7, I$, моменты откликов на вступления сейсмических волн более выражены, чем в рассмотренных выше случаях, однако надежное распознавание событий и оценка их параметров оказались возможными только после применения фильтрации принятых сигналов (рис. 7, II).

В таблице 2 сведены временные и частотные параметры зарегистрированных слабых землетрясений, волновые формы которых представлены на рис. 2-7.

Особый интерес представляет определение магнитуд слабых сейсмических событий по длительности их гидроакустических откликов. Однако мелководные 

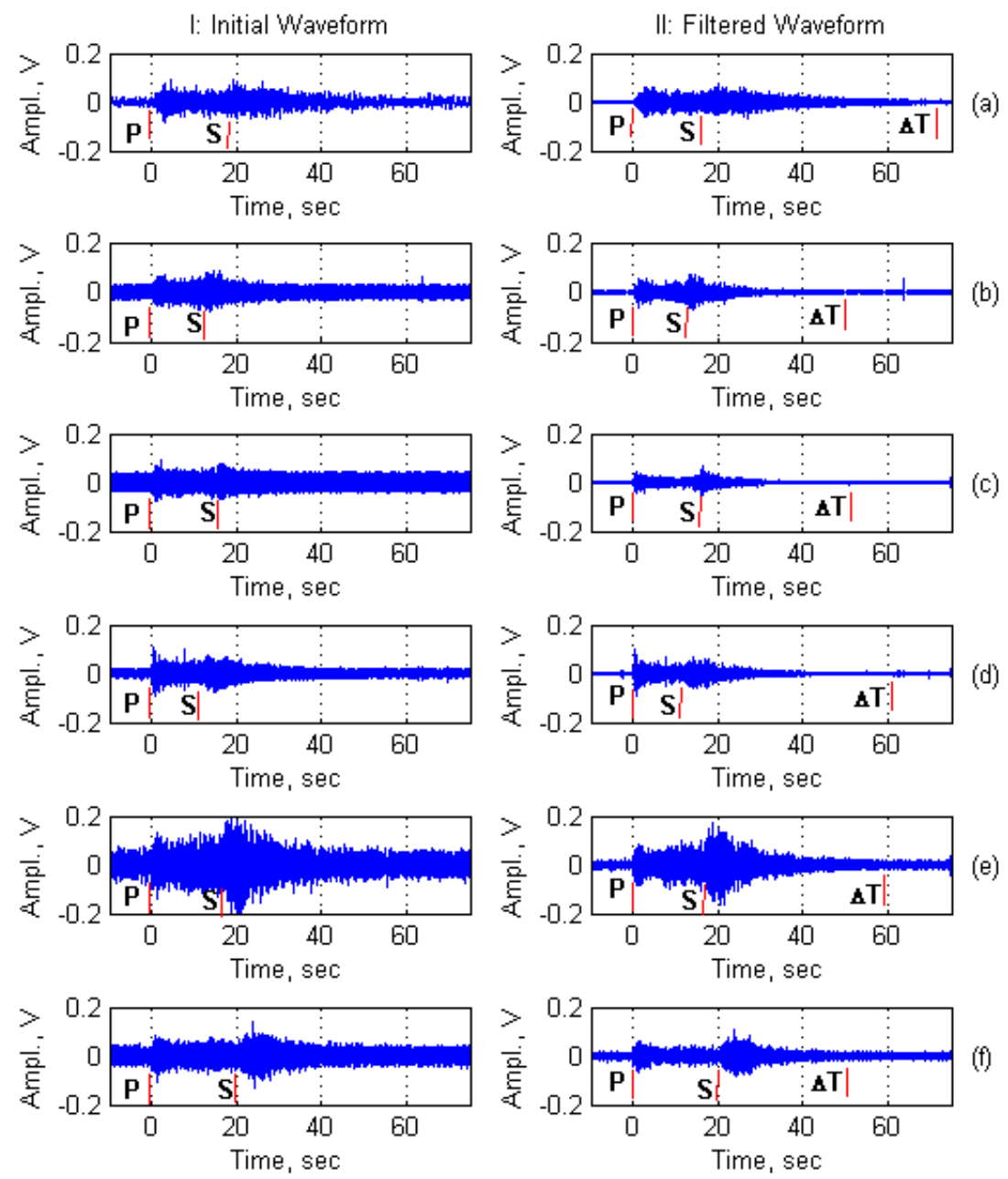

Рис. 7. Первичные (I) и отфильтрованные (II) волновые формы землетрясений, зарегистрированных гидрофонной станцией: (a) - № 1511 (дата - 10.08.2007 г., время - 11:02:53.4; D=120 км, K=8.8); (b) - № 1520 (дата - 11.08.2007 г., время - 23:55:21.4; $\mathrm{D}=99$ км, K=7.5); (c) - в бюллетене не отмечено (дата - 12.08.2007 г., время - 19:42:40); (d) - в бюллетене не отмечено (дата - 13.08.2007 г., время - 01:48:41); (e) - № 840 (дата - 19. 05.2009 г., время - 20:44:53.5; D=122 км, K=9.2); (f) - № 843 (дата - 20.05.2009 г., время - 06:53:10.7; D=161 км, $\mathrm{K}=8.1)$.

Fig. 7. Initial $(I)$ and filtered $(I I)$ wave shapes of earthquakes recorded by the hydrophone station: (a) - № 1511 (at 11:02:53.4 on 10.08.2007; $\mathrm{D}=120 \mathrm{~km} ; \mathrm{K}=8.8$ ); (b) - № 1520 (at 23:55:21.4 on 11.08.2007; $\mathrm{D}=99 \mathrm{~km} ; \mathrm{K}=7.5$ ); (c) - not included in the bulletin (at 19:42:40 on 12.08.2007); (d) - not included in the bulletin (at 01:48:41 on 13.08.2007); (e) - № 840 (at 20:44:53.5 on 19.05.2009; D=122 km; K=9.2); (f) - № 843 (at 06:53:10.7 on 20.05.2009; $\mathrm{D}=161 \mathrm{~km} ; \mathrm{K}=8.1)$.

наблюдения в закрытых акваториях накладывают свои ограничения на применение известных существующих соотношений (например [Brocher, 1983; Solov'ev, Kovachev, 1996]), полученных по результатам глубоководных наблюдений. Так, существенный вклад в длительность события вносит реверберация, которая в условиях мелководья сильнее зависит от региональных особенностей геологического строения и от направления прихода сейсмической энергии. Кроме этого, большинство известных результатов сопоставления длительности и магнитуды получены для узкополосных наблюдений с помощью донных сейсмографов. Проведенные оценки магнитуд по формуле Брочера $\mathrm{Mb}=2.30+\lg (\tau)$ [Brocher, 1983] и по соотношению $\mathrm{M} 1=1.38 \ln (\tau)-3.63$, построенному авторами в работе
[Levin et al., 2010] по калибровочной таблице Соловьева-Ковачева [Solov'ev, Kovachev, 1996], показали, что оценку магнитуды, более близкую к определенным на сейсмостанции «Южно-Курильск», дает формула Брочера. Однако, ввиду большого разброса значений вопрос о связи длительности слабых сейсмических событий, зарегистрированных широкополосными гидрофонными станциями на мелководье, с их энергетическими характеристиками требует дополнительной проработки и увеличения статистики таких наблюдений.

Гидроакустические наблюдения на острове Шикотан проводились в бухте Хромовой в период с 18 по 22 июня 2009 г. В этот период наблюдений геоакустическая эмиссия, связанная с подготовкой землетрясений, 
A.S. Borisov et al.: Hydroacoustic observations of weak earthquakes...

T а б л и ц а 2 2. Временные и частотные параметры зарегистрированных слабых землетрясений

$\mathrm{T}$ a b l e 2. Time and frequency parameters of recorded weak earthquakes

\begin{tabular}{|c|c|c|c|c|c|}
\hline № землетрясения & Класс (К) & $\begin{array}{l}\text { Удаленность } \\
\text { (D), км }\end{array}$ & $\begin{array}{l}\text { Время между вступлениями } \\
\text { Р- и S-волн*, с }\end{array}$ & $\begin{array}{l}\text { Длительность события } \\
(\Delta \mathrm{T}), \text { с }\end{array}$ & $\begin{array}{l}\text { Диапазон частот, } \\
\text { Гц }\end{array}$ \\
\hline $\begin{array}{l}\text { № } 1516 \\
\text { (рис. 2) }\end{array}$ & 10.6 & 665 & $70(65.1)$ & 110 & 75 \\
\hline $\begin{array}{l}\text { № } 833 \\
\text { (рис. 3) }\end{array}$ & 10.4 & 125 & $17(18.2)$ & 62 & 100 \\
\hline $\begin{array}{l}\text { № } 1515 \\
\text { (рис. 4) }\end{array}$ & 6.7 & 182 & 22 (19.3) & 98 & 100 \\
\hline $\begin{array}{l}\text { Не отмечено } \\
\text { (рис. 6) }\end{array}$ & - & - & 13 & 48 & 100 \\
\hline $\begin{array}{l}\text { № } 1511 \\
\text { (рис. } 7, a \text { ) }\end{array}$ & 8.8 & 120 & $16(13.4)$ & 72 & 90 \\
\hline $\begin{array}{l}\text { № } 1520 \\
\text { (рис. } 7, b \text { ) }\end{array}$ & 7.5 & 99 & $13(11.3)$ & 48 & 100 \\
\hline $\begin{array}{l}\text { Не отмечено } \\
(\text { рис. } 7, c)\end{array}$ & - & - & 16 & 46 & 100 \\
\hline $\begin{array}{l}\text { Не отмечено } \\
\text { (рис. } 7, d)\end{array}$ & - & - & 12 & 61 & 100 \\
\hline $\begin{array}{l}\text { № } 840 \\
\text { (рис. } 7, e \text { ) }\end{array}$ & 9.2 & 122 & $17(16)$ & 59 & 100 \\
\hline $\begin{array}{l}\text { № } 843 \\
\text { (рис. } 7, f \text { ) }\end{array}$ & 8.1 & 161 & $20(20.2)$ & 50 & 100 \\
\hline
\end{tabular}

П р и м е ч а н и е. * - в скобках приведены значения, определенные на сейсмостанции «Южно-Курильск».

$\mathrm{N}$ o t e. * - values in brackets are determined at the Yuzhno-Kurilsk Seismic Station.

не наблюдалась, но также были зарегистрированы гидроакустические сигналы от нескольких слабых землетрясений. Для примера на рис. 8 приведена осциллограмма и спектрограмма одного из этих событий, длительностью $\Delta \mathrm{T}=47$ с, имеющего характерный для землетрясений непрерывный шумоподобный спектр акустических (механических) колебаний. Как и при гидрофонных наблюдениях на Кунашире, спектр сигнала от землетрясений занимает довольно широкую полосу частот, порядка 100 Гц. Время между вступлениями Р- и S-волн - 13 с. (Частота «оцифровывания» сигнала в данном случае была равна 1000 Гц). Гидрофонные записи на Шикотане (в бухте) отличаются наличием более интенсивных естественных помех, чем на Кунашире (в озере).

20 июня 2009 г. было зарегистрировано одно местное микроземлетрясение (М3) (рис. 9). Начало записи соответствует 12 ч 25 мин 54 с местного времени. Это МЗ вызвало в бухте довольно интенсивные акустические колебания. На рис. 9 видно, что уровень акустического сигнала от этого МЗ превышает в несколько раз средний уровень акустических помех в бухте. Представляется очевидным, что гидрофон оказался в районе эпицентра данного МЗ. Это видно и по уровню сигнала (рис. 9, $a, b)$, и по наличию мощных высокочастотных - от 100 Гц до 250 Гц - спектральных составляющих в сигнале (частота дискретизации записи была равна 500 Гц), а также по отсутствию временного расхождения продольных и поперечных волн. Наличие интенсивных высокочастотных составляющих в спектре сигнала, вызванного МЗ, указывает также на то, что и гипоцентр этого события находился сравнительно неглубоко, вероятнее всего в верхней кромке коренных пород.

Из осциллограммы самого события (рис. 9, b) видно, что длительность активной фазы М3 составляет приблизительно 20 с. Под активной фазой МЗ мы здесь понимаем время развития трещины (трещин). По времени продолжительности активной фазы это М3 можно отнести к разряду слабых землетрясений [Levin et al., 2010]. На рис. 10 показан фрагмент записи начальной стадии МЗ. Это МЗ интересно тем, что его предваряет низкочастотный упреждающий сигнал. Обычно сейсмостанции редко регистрируют НУСы от удаленных событий даже со значительными магнитудами [Levin, Sasorova, 1994]. В первую очередь это связано с тем, что низкочастотные упреждающие сигналы имеют очень малые уровни, как правило, гораздо меньшие, чем уровни естественных помех. Обнаружение слабого НУС перед МЗ также подтверждает то обстоятельство, что МЗ произошло на относительно малом расстоянии от места регистрации. Конечно, НУС у МЗ имеет значительно меньшую длительность (для рассматриваемого случая $\Delta \mathrm{t} \sim 0.2$ с, что составляет $0.28 \%$ от общей длительности М3), и более высокие частоты колебаний (20 Гц в нашем случае). Вероятнее 



(b)

Рис. 8. Волновая форма $(a, c)$ и спектрограмма $(b, d)$ землетрясения, зарегистрированного гидрофонной станцией 19.06.2009 г. в бухте Хромовой: $a, b$ - первичная запись; $c, d-$ сигнал после фильтрации.

Fig. 8. Wave shape $(a, c)$ and spectrogram $(b, d)$ of the earthquake recorded by the hydrophone station in Khromovaya Bay on 19.06.2009: $a, b$-initial record; $c, d$ - signal after filtering.

всего, НУСы представляют собой сигналы от «тихих» или «медленных» землетрясений. Представляется, что НУСы при МЗ появляются при резонансных возбуждениях собственных колебаний локальной геологической структуры (тела) в результате трения об нее окружающих пород (геологических структур) при их относительных перемещениях, происходящих в результате воздействия неоднородных механических напряжений на объемы геологических сред. Красными стрелками на рис. 9 и 10 отмечен момент начала приема гидроакустического сигнала от М3.

\section{4. ЗАКЛЮЧЕНИЕ}

В статье представлены результаты гидрофонных наблюдений слабых землетрясений на Курильских островах Кунашир и Шикотан. Наблюдения проводились в рамках экспедиционных работ в августе 2007, сентябре 2007 и мае 2009 г. При проведении наблюдений были зарегистрированы и записаны гидроакустические сигналы от слабых региональных землетрясе-


(b)

Рис. 9. Волновая форма $(a, b)$ землетрясения, зарегистрированного гидрофонной станцией 20.06.2009 г., о. Шикотан, бухта Хромовая.

Fig. 9. Wave shape $(a, b)$ of the earthquake recorded by the hydrophone station in Khromovaya Bay (Shikotan) on 20.06.2009.

ний. Часть этих землетрясений была зарегистрирована и сейсмостанцией «Южно-Курильск», а часть - только гидрофонной станцией. Особенностью наблюдений являлось то, что измерения проводились на мелководье: на озере Лагунном (о. Кунашир) и в бухте Хромовой (о. Шикотан).

Анализ гидроакустических записей с гидрофонной станции показал, что заметной предваряющей реакции региональной геосреды на слабые региональные события не произошло, т.е. геоакустической эмиссии не наблюдалось ни до подготовки, ни в другие этапы событий. Процесс подготовки МЗ также не вызвал заметной геоакустической эмиссии.

В работе показано, что, несмотря на неблагоприятную помеховую обстановку, даже слабые землетрясе-

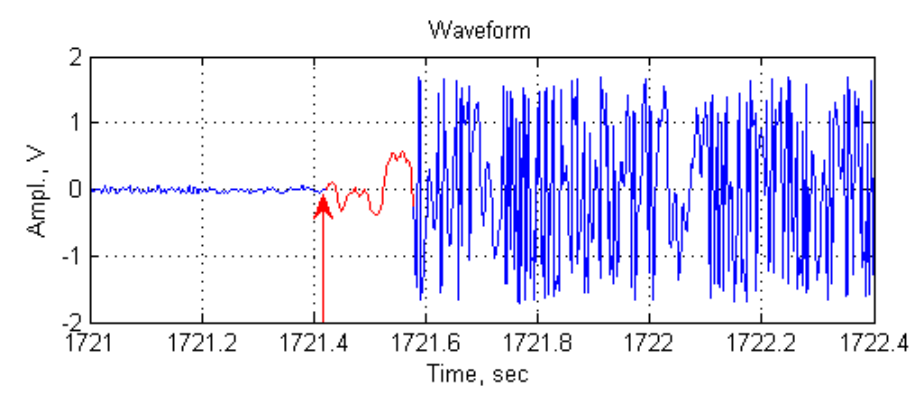

Рис. 10. Низкочастотный упреждающий сигнал.

Fig. 10. Low-frequency preceding signal. 
ния уверенно регистрируются гидрофонными станциями, а применение соответствующей обработки сигналов дает возможность выделять моменты вступления сейсмических волн и измерения их параметров. В работе установлено также, что частотный спектр акустических сигналов от слабых землетрясений, воспринимаемых гидрофонными станциями, установленными в озере Лагунном (о. Кунашир) и в бухте Хромовой (о. Шикотан), носит непрерывный шумоподобный характер в диапазоне частот до 90-100 Гц (для землетрясений, удаленных на 100-200 км от места регистрации). В случае землетрясения, эпицентр которого был расположен на расстоянии 665 км, диапазон занимаемых событием частот располагался в области до 75 Гц.
Показано, что некоторым слабым землетрясениям и М3 может предшествовать НУС, вероятно, представляющий собой сейсмоакустический отклик на подвижку геологического массива (глыбы) перед сейсмическим разрывом («тихое» землетрясение, крип). Акустические сигналы от подобных «тихих» перемещений пород (НУСы) могут служить сверхкраткосрочными признаками события.

В заключение отметим, что в Институте морской геологии и геофизики ДВО РАН в настоящее время разработан один из вариантов малогабаритных автономных гидрофонных станций с продолжительностью непрерывной регистрации, равной трем месяцам. Несколько гидрофонных станций этого типа будут устанавливаться на Курильских островах и Сахалине.

\section{5. ЛИТЕРАТУРА}

Brocher Th.M., 1983. T-phases from the earthquake swarm on the Mid-Atlantic ridge at 31.6 N. Marine Geophysical Research 6 (1), 39-49. http://dx.doi.org/10.1007/BF00300397.

Lappo S.S., Levin B.W., Sassorova E.V., Morozov V.E., Didenkulov I.N., Karlik Ya.S., 2003. Hydroacoustic location of an oceanic earthquake origin area. Doklady Earth Sciences 389 (2), 229-232.

Levin B.V., Sasorova E.V., 1994. Seismic-wave low-frequency forerunner of earthquake preparation. Vulkanologiya i seismologiya 4-5, 128-132 (in Russian) [Левин Б.В., Сасорова Е.В. Сейсмоволновой низкочастотный предвестник подготовки землетрясения // Вулканология и сейсмология. 1994. № 4-5. С. 128-133].

Levin B.W., Sasorova E.V., Borisov S.A., Borisov A.S., 2010. Estimating the parameters of small earthquakes and their signals. Journal of volcanology and seismology 4 (3), 203-212. http://dx.doi.org/10.1134/S074204631003005X.

Solov'ev S.L., 1968. Development of hydroacoustic studies of submarine earthquakes. Vestnik AN SSSR 11, 77-80 (in Russian) [Соловьев С.Л. Развитие работ по гидроакустике подводных землетрясений // Вестник АН СССР. 1968. № 11. C. 77-80].

Solov'ev S.L., Ferry M., Kyzin I.P., Kovachev S.A., 1989. Seismicity of the Earth's crust in the south-eastern part of the Tyrrhenian Sea (based on seabed and land seismic observations). Doklady AN SSSR 305 (6), 1339-1343 (in Russian) [Соловьев С.Л., Ферри М., Кузин И.П., Ковачев С.А. Сейсмичность земной коры юго-восточной части Тирренского моря (по результатам совместных донных и наземных сейсмологических наблюдений) // Доклады АН CCСР. 1989. T. 305. № 6. С. 1339-1343].

Solov'ev S.L., Kovachev S.A., 1996. Estimating the local magnitude of minor earthquakes from ocean-bottom seismograph observations. Izvestiya, Physics of the Solid Earth 32 (5), 417-421.



Борисов Александр Сергеевич, канд. техн. наук Институт морской геологии и геофизики ДВО РАН 93022, Южно-Сахалинск, ул. Науки, 1б, Россия 凶e-mail: borisov_as@imgg.ru

Borisov, Alexander S., Candidate of Technical Sciences Institute of Marine Geology and Geophysics FEB RAS 693022, Yuzhno-Sakhalinsk, Nauki street, 1b, Russia

$\bowtie$ e-mail: borisov_as@imgg.ru 

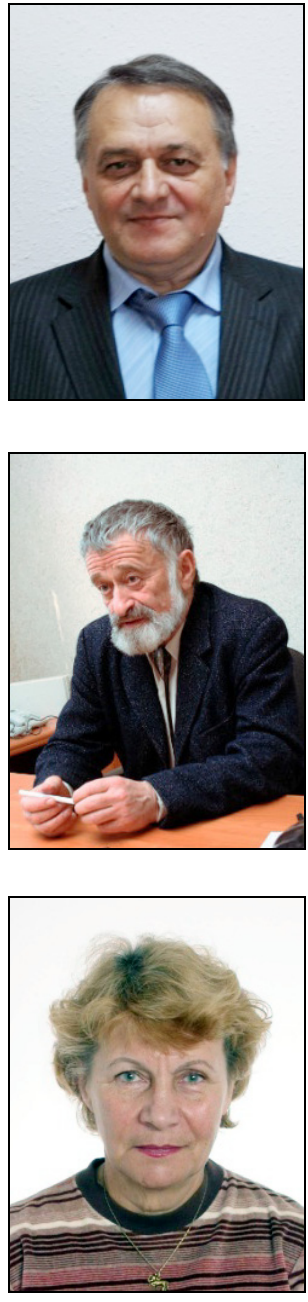

Борисов Сергей Александрович, докт. техн. наук Институт морской геологии и геофизики ДВО РАН 93022, Южно-Сахалинск, ул. Науки, 1б, Россия e-mail: borisov@imgg.ru

Borisov, Sergey A., Doctor of Technical Sciences Institute of Marine Geology and Geophysics FEB RAS 693022, Yuzhno-Sakhalinsk, Nauki street, 1b, Russia e-mail: borisov@imgg.ru

Левин Борис Вульфович, член-корреспондент РАН Институт морской геологии и геофизики ДВО РАН 93022, Южно-Сахалинск, ул. Науки, 1б, Россия e-mail: lbw@imgg.ru

Levin, Boris W., Corresponding Member of RAS Institute of Marine Geology and Geophysics FEB RAS 693022, Yuzhno-Sakhalinsk, Nauki street, 1b, Russia e-mail: lbw@imgg.ru

Сасорова Елена Васильевна, докт. физ.-мат. наук Институт океанологии РАН

117997, Москва, Нахимовский проспект, 36, Россия

Sarosova, Elena V., Doctor of Physics and Mathematics Institute of Oceanology RAS

117997, Moscow, Nakhimosky pr., 36, Russia 